\title{
AUTOMATIC SYSTEMS FOR CONTROLLING FRUIT MOVEMENT, GRADING AND STORING UNDER LOW TEMPERATURE CONTROLLED ATMOSPHERE STORAGE
}

\author{
D. RAMESH BABU ${ }^{1}$, N. GAYATRI ${ }^{2}$, P. ISSAC PRASAD ${ }^{3}$, S. JAGAN MOHAN RAO ${ }^{4} \&$ \\ K V. NARASIMHA RAO ${ }^{5}$
}

${ }^{1}$ Assistant Professor, Department of Mechanical Engineering, S R Engineering College, Warangal, Telangana and Research Scholar, Department of Mechanical Engineering, Koneru Lakshmaiah Education Foundation, Vaddeswaram,

Guntur, Andhra Pradesh, India

${ }^{2}$ Assistant Professor, Department of Computer Science and Engineering, Kakatiya Institute of Technology and Science, Warangal, Telangana, India

${ }^{3,5}$ Professor, Department of Mechanical Engineering, Koneru Lakshmaiah Education Foundation, Vaddeswaram, Guntur, Andhra Pradesh, India

${ }^{4}$ Professor Department of ECE, Ramachandra College of Engineering, Eluru, Andhra Pradesh, India \begin{abstract}
Cold storage units preserve fresh produce for extended shelf life. Operation of cold stores at present in India is done with multi commodity and common storage chambers where compatibility of fresh produce is not taken care of. Parameters to be maintained in the cold stores are: temperature of produce, temperature of the cooling coil, air temperature, humidity level, gas composition like oxygen, carbon-dioxide, ethylene, etc. for different fruits and vegetables to be stored in different chambers. These parameters need to be closely maintained to get best storage life of the produce. Most of the storage plants in India are equipped with manual or semi-automatic controls. Centralized chambers holding all types of fruits and vegetables at one place can lead to improper maintenance of storage conditions causing reduced life. The purpose of this study is to identify the technical requirements of computerized and automatic systems, so that fresh produce can be handled on automatic material handling systems. Apple color quality was measured by an expert panel and compared with colorimeter grading system. Significant positive correlation was found between visual and colorimeter readings. Computerized systems for refrigeration systems, data logging is to be installed for careful monitoring of cooling and gas conditions inside the chambers. This will ensure fruits and vegetable stored at optimal shelf life conditions. The results of this study can help to develop software for a comprehensive cold storage warehouse management system.

KEYWORDS: Fruits and Vegetables, Color, Automatic Sorting-Grading, Cold Store, Controlled Atmosphere Store (CAS) \& Automation
\end{abstract}

Received: Jun 09, 2020; Accepted: Jun 29, 2020; Published: Jul 23, 2020; Paper Id.: IJMPERDJUN2020430

\section{INTRODUCTION}

Commercial cold storage units preserve fruits, vegetables, cashew nut, raisins, red chilli, Bengal gram, ice creams, cheese, butter, meat, frozen green peas, etc. to control the spoilage and retain the quality parameters. Shelf life of these products depends on the moisture content of the product, respiration rate, temperature of the cold store chamber, relative humidity $(\mathrm{RH})$ etc. Fresh produce like fruits and vegetables require low temperatures of the order 
of 1 to $15^{0} \mathrm{C}$. Frozen products like ice creams, meat need to be preserved at -18 to $-12^{0} \mathrm{C}$. Relative humidity requirements are also different for different products. Fresh produce require RH levels of $85-95 \%$ and dry products like red chilli, raisins, cashew nut require low $\mathrm{RH}$ in the range of 40 to $70 \%$. This is due to the requirement of avoiding moisture loss (in case of fruits and vegetables), avoiding moisture gain (in case of low moisture foods like dry fruits and grains).

Cold store units are equipped with refrigeration systems to lower the temperature of the air inside the storage chamber, which will reduce the temperature of the produce and maintain the low temperature. Due to respiration of fresh produce, heat is generated and the same has to be removed continuously. This necessitates the running of compressors when required.

The temperature and gas conditions inside the storage chambers are very important apart from RH. Labor intensive handling in cold stores is most common in India. This is due to lack of awareness among cold store owners on automatic systems availability for unloading, loading, sorting, grading, packing and storage. Centralized computer with PLCs can monitor the storage chambers. Several manufacturers developed technologies to centrally control and log the data of temperature, $\mathrm{RH}$, gas conditions. The present investigation is made to review the needs of automation required in cold stores/controlled atmosphere stores and suggest suitable systems for automatic control and remote monitoring of all the parameters for better shelf life of produce. Efficiency and low labour cost can be achieved using conveyer and grading lines, which are thoroughly discussed in this paper.

\section{LITERATURE OVERVIEW}

Development of fruit storage plants in the shape of cold stores is very important for saving national waste of farmers' produce. Absence of adequate cold storage facilities cause loss of fruits and vegetables produced [1-3].

Narasimha Rao et al. (1992, 1993a) reported the importance of pre-cooling of fruits using numerical modeling. They reported their numerical results with fruits and vegetables with spherical geometry [4-5]. Narasimha Rao et al (1993b) reported about the bulk-hydraircooling of fruits [6]. Several studies reported the need of infrastructure building in fruit and vegetable preservation including ripening facilities of fruits. Ramesh Babu et al. reported the critical requirements of CA Stores and ripening facilities [7-10].

Ram Deshmukh et al. (2020) investigated the pressure testing and gas tightness of CA chambers and modeled the pressure loss in the chambers. They categorized the chambers into low oxygen, ultra-low oxygen and high oxygen chambers based on rate of pressure loss in the hermetically sealed chambers [11]. Developing technologies for preserving agri produce and projects are thoroughly reported by several researchers [12-14]. Pre-Cooling and refrigeration requirements for mango and banana fruits are reported using mathematical modeling by Narasimha Rao et al. (2020a, 2020b) $[15,16]$.

Machinery manufacturers use advanced tools and mechanized systems for fruit conveying, sorting, grading and packing apart from gas control systems. Popular manufacturers for fruit sorting, grading and CA systems are M/s Aweta, M/s Unisorting, M/s ICA, M/s Storage Control systems, M/s Van Amerongen, M/ Isolcell etc. Refrigeration system manufacturer's are M/s Heat craft, M/s Bohn, M/s Bitzer, M/s Carrier, M/s Rinac, M/s Blue star etc., Reputed manufacturers for material handling for cold store applications are M/s Godrej, M/s Crown, M/s Nilkamal, M/s Voltas, M/s etc., [17-21]. 

under Low Temperature Controlled Atmosphere Storage

\section{Technical Requirements of Cold Store for Automation and Computer Control}

- Sensors for cool air

- Sensor for refrigeration system

- Sensor for measuring product temperature at different locations.

- Sensor for Relative Humidity

- $\quad$ Sensor for Ethylene (C2H4)

- $\quad$ Sensor for $\mathrm{O} 2$

- Sensor for carbon-dioxide

- Sensor for refrigerant leakage, if any.

Sensors for cool air: Every storage chamber need to be equipped with temperature sensors for measurement of air, return air, fruit temperature at two locations within the storage bin pierced into the apple samples.

Sensor for RH: RH sensor can be installed in the return air near evaporator to measure the relative humidity of air. This can be connected to the central SCADA/Monitoring system and data logging.

Measurement of temperature and RH continuously: Data log systems need to be installed with each storage chamber to continuously record the temperature, RH and other gas compositions. SCADA systems of following makes are found best suitable for this purpose.

All these systems must be integrated with a central console with HVAC monitoring systems like, PlantvisorPro (M/s Carel) or any SCADA software package.

Figures 1 and 2 show the centralized monitoring and controlling systems for cooling and air conditioning.

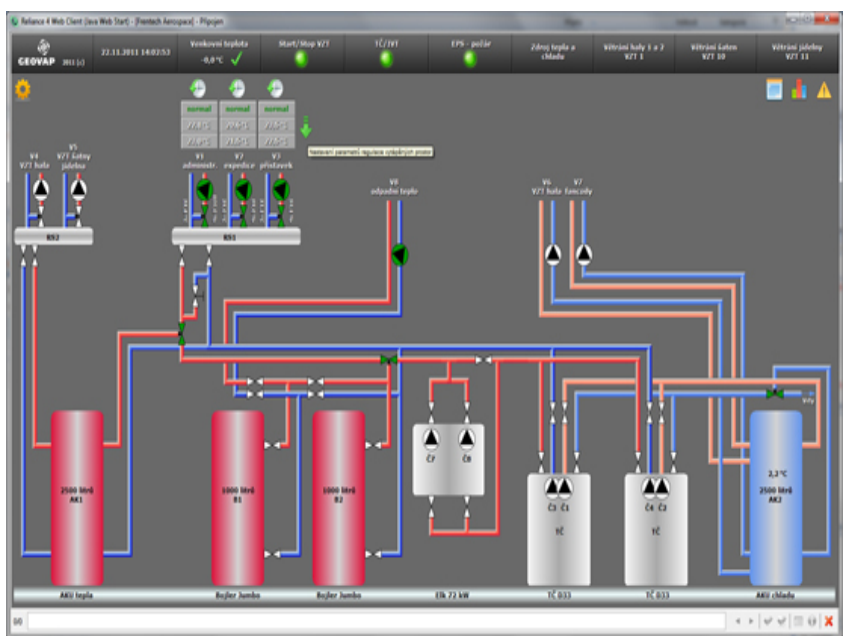

Figure 1: Centralized monitoring and controlling system for heating and cooling (Reliance SCADA for HVAC). 


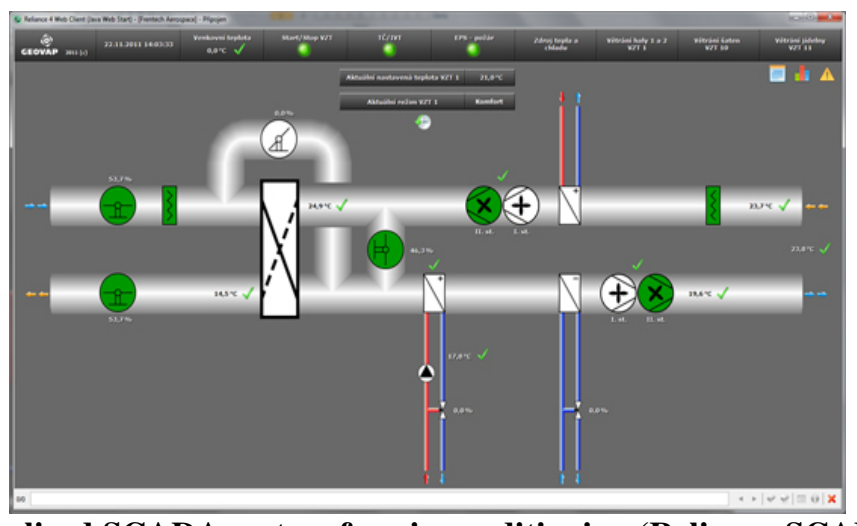

Figure 2: Centralized SCADA system for air conditioning (Reliance SCADA for HVAC)

Figures 3 and 4 show the PLC systems suitable for HVAC applications with remote monitoring facility. Remote monitoring helps the technical team to manage the systems from remote locations during non-working hours. This helps to safeguard the produce from unwanted fluctuations in parameters due to machine breakdowns.

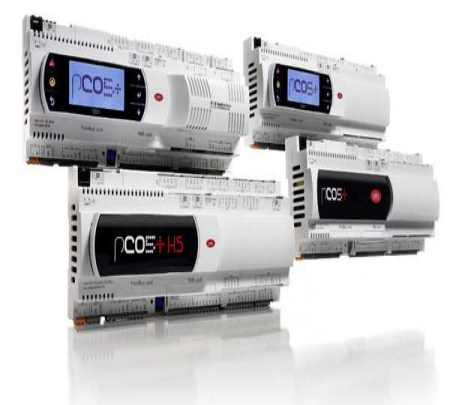

Figure 3: Programmable Logic Controller for installing to each de-centralized storage chamber (Carel Make)

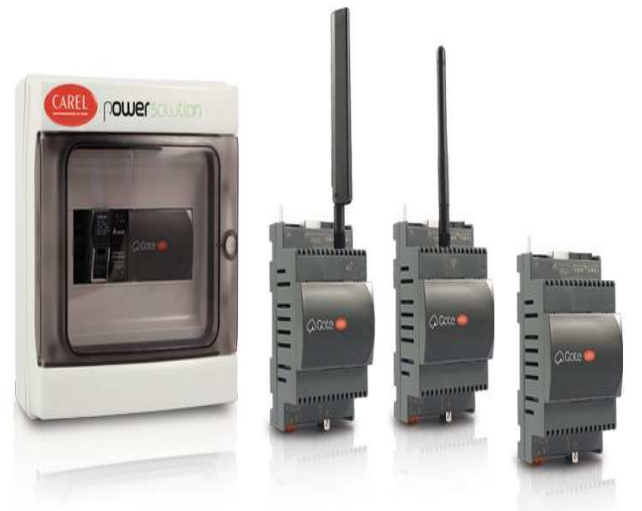

Figure 4: Remote monitoring systems -Gateway IOT (Internet of Things) Make: M/s Carel)

The most important equipment and machinery are discussed below. Upon the failure of these systems, produce quality is adversely affected. Minor equipment is not discussed in this paper.

\section{Refrigeration Equipment for Cooling the Produce}

The capital and running costs of the cooling equipment depend on the design aspects and optimal utilization. Environmental and safety aspects are considered while designing the equipment. Non-toxic and non-flammable refrigerants like R404A, R134a can be used for cooling system. Variable Frequency Drives (VFD) should be installed on 
the compressor racks, condenser pumps and fans for saving the energy.

\section{Design of High Relative Humidity Sensible Cooling Evaporators with Low $\Delta T$}

Evaporators should be designed to maintain low $\Delta \mathrm{T}$ for sensible cooling, thereby avoiding moisture loss from the air and maintaining high $\mathrm{RH}$.

\section{Nitrogen Generators}

PSA (pressure swing adsorption) technique should be used to make 99\% nitrogen. Molecular sieves are to be used for separating the nitrogen from atmosphere air. Low oxygen is reached by pumping pure nitrogen gas through electrically operated solenoid valves. PSA technology consumes low energy.

\section{5. $\mathrm{CO}_{2}$ Scrubbers}

The scrubbers remove excess carbon dioxide from the storage space. Some quantity of ethylene is also removed by them. Carbon molecular sieves and activated alumina are the adsorbents used in the scrubbers. Sieves are regenerated automatically at fixed intervals controlled by the PLC unit. The life of sieves depends on usage and level of Co2 Production. In general manufacturers provide guarantee of 5 to 10 years (Make: SCS, USA). This may vary from manufacturer to manufacturer.

Other established manufacturers of $\mathrm{Co} 2$ absorbers are:

- $\mathrm{M} / \mathrm{s}$ Van Amerongen

- $\mathrm{M} / \mathrm{s}$ Isolcell

Figures 5 and 6 show the $\mathrm{CO} 2$ scrubbers for fruit storage plants specifically for controlled atmosphere storage. This equipment scrubs the excess Carbon-di-Oxide from the chambers and protects the fruits from high $\mathrm{CO} 2$ disorders. Since the systems are in closed loop with the chamber and mounted external to the chamber, no heat is added to the chamber due to operation.

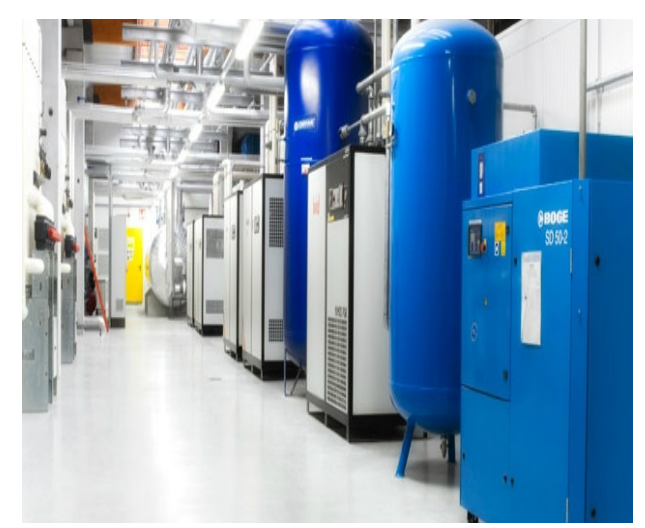

Figure 5: CO2 Scrubber system (M/s Isolcell) 


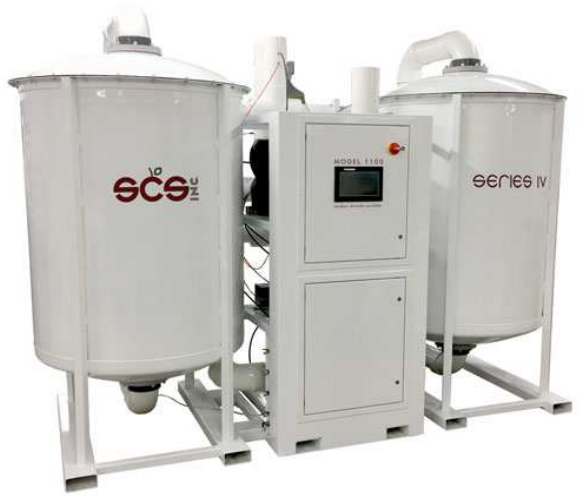

Figure 6: CO2 Scrubber latest model of M/s Storage Control Systems

\section{Monitoring, Controlling and Recording Instruments}

- Oxygen and Carbon dioxide analyzers

- $\quad$ Devices for precise control of oxygen and carbon dioxide

- Data log and recording the parameters for analysis of conditions in the storage chambers and containers.

\section{Material Handling Systems}

Manual handling of fruit boxes consume lot of time and effort. Following systems are recommended to be used in cold stores for efficient operations:

- Hydraulic hand pallet trucks

- $\quad$ Power pallet trucks

- $\quad$ Sorting-Grading machine with Bin fillers

- $\quad$ Electric Forklift trucks

- $\quad$ Electric Stackers

\section{Details of Material Handling Equipment Required}

Most of the cold stores in India use labour for shifting of fruit boxes during sorting, grading-packing operations. This leads to mis-handling and surface bruising of the delicate fruits. This causes increase in respiration of fruits, leading to quicker degradation (Ramesh Babu et al., 2018). Some of the techniques to avoid multiple handling and damage to fruit boxes are listed below:

Wooden pallets/Plastic pallets: Size - 1200mm x 1000mm x 200mm. Pallets are compatible to the forks of the forklifts for easy and quick handling.

Hydraulic Hand pallet trucks: Capacity 1MT, Lift height: $100 \mathrm{~mm}$. These are used to:

- move loaded pallets from the dock area to the Sorting-grading machine or store directly

- $\quad$ bring the empty bins from the bin washing area to the bin fillers

- move empty wooden pallets from the sorting-grading machine to the dock area 
- Move any other material as and when required.

Power pallet truck: Capacity: 2 MT. They perform following duties:

- To carry the palletized fruit boxes from the dock receiving area to the weighment area

- To shift the loaded wooden pallets to the sorting-grading feeding conveyer

- To shift the apple filled bins from bin filler area to the weighment area

- To shift miscellaneous items like empty cartons, empty bins, wooden pallets, etc.

Electric forklift truck, Capacity: 3MT, Lift height 5.5m, Type: Battery operated.

Reputed suppliers for material handling systems for fruit storage plants are:

- $\mathrm{M} / \mathrm{s}$ Godrej

- $\mathrm{M} / \mathrm{s}$ Crown

- $\mathrm{M} / \mathrm{s}$ Nilkamal

- $\mathrm{M} / \mathrm{s}$ Voltas, etc.

It is recommended to use electrically operated vehicles. These will avoid emission unlike diesel operated forklifts and other equipment. Any gases entered into the fruit storage chambers can harm the produce stored.

8. Sorting-grading machine: This machine is designed for carrying sorting, grading of round shaped fruits. Capacity of the machine is 10 MT per hour. Four bin fillers are provided to fill 4 bins (of $300 \mathrm{~kg}$ capacity each) at a time. A 5th exit is provided for cull fruit/non-categorized fruits. The machine is equipped with sensors for automatic fruit movement on conveyers, grading and bin filling. It contains facilities for washing, wiping, sorting, color grading, size grading and bin filling. Computerized programs with color and size grading algorithms are used for grading of fruits. The manufacturer of the machine is M/s Sammo, Italy with grading software from M/s Ellipse, Italy.

As a case study, the above machine details are provided. However, alternative machine suppliers are available for providing sorting, grading and packing machines are:

- $\mathrm{M} / \mathrm{s}$ Aweta

- $\mathrm{M} / \mathrm{s}$ Greefa

- $\mathrm{M} / \mathrm{s}$ Unitec

- M/s Unisorting.

The technical details of the material handling systems of the sorting-grading line are given below.

Apple Sorting and Refilling Lines into Bins: Fruit that can be sized, Average weight: $140 \mathrm{gm}$, Min. Dia 30mm. Max. Dia 110 mm. Plastic or wooden boxes 15-20 kg or similar (400x600x 300). Plastic/wooden bins 1200 x 1000 x 770 approx, Capacity: 10 Tons/h.

Size: Ellips True sort (M/s Ellips) can measure the size accurately with faster results. Accuracies achievable are $0.1 \mathrm{~mm}$. Pictures are captured from all directions of fruit using cameras and mirrors around the moving conveyer carrying 
apples. This data is sent to the central control and computer system for True sort operation. A mechanical lever operates to unload the fruit gently to different conveyers to fill into different bins based on size required. The software is equipped with fruit classes and statistical measurements, so that each farmer can be checked for quality fruit supplied and payments can be made to them accordingly.

Figures 7 and 8 show the grading system of fruits. Fruit diameter is measured using CCD cameras; Software measures the diameter from the data transmitted through Profibus. Color measurement is done on all sides of the fruits while the conveyers move carrying fruits under the camera box. Several algorithms of software rapidly evaluate the Lightness, a value and b value apart from Chroma and Hue value. The system segregated the fruits based on the color \% required. Either redness or greenness can be precisely controlled for apples.

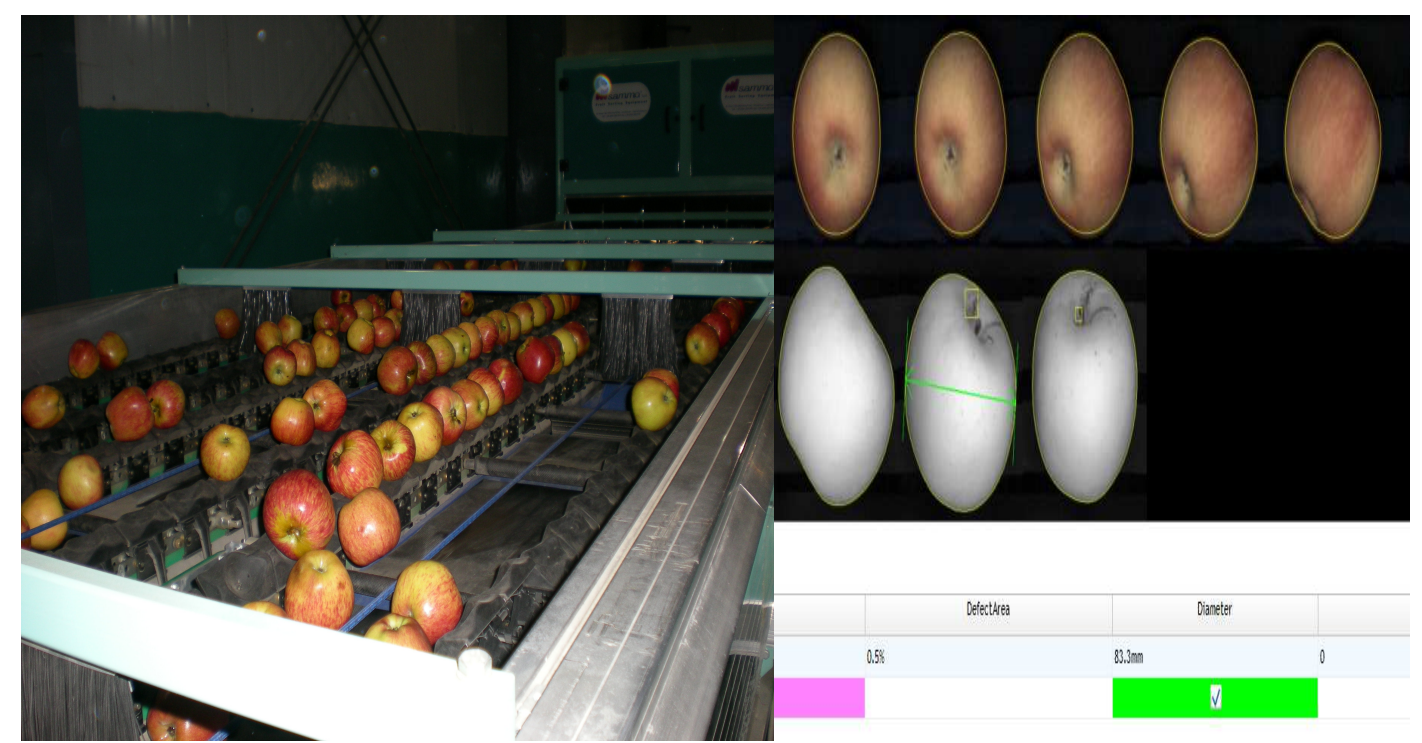

Figure 7: Sorting grading operation (Courtesy: M/s Sammo, Italy)

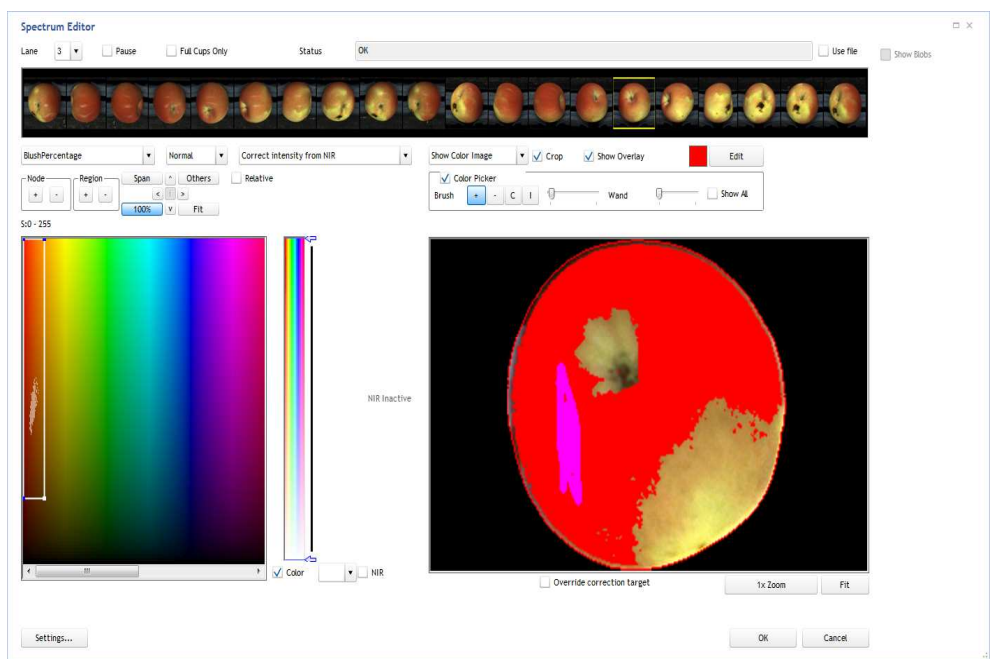

Figure 8: Color grading system using Hunter $\mathrm{L}, \mathrm{a}, \mathrm{b}$ and total color difference $\Delta \mathrm{E}$ (Courtesy: M/s Sammo in collaboration with Ellips software).

\section{Sorting-Grading Line Composition}

- Automatic Bin Dumper: The machine includes: motorized chain conveyor for 2 full bins placed in the below parttilting chair for gentle unloading-gravity conveyor in the upper part for two empty bins. 
- Roller Conveyor for Manual Boxes Emptying mod. 0.8mm x 3.0m: Complete with receiving hopper covered with soft rubber Speed variator.

- Connecting Conveyor with 3 belts: With deviator.

- Feeding Belt mod. 1.300m x 1.500m: Complete with photocell to control the stop start of the dumper.

- Sorting Table mod. $1.3 \mathrm{~m}$ x $3.5 \mathrm{~m}$ (useful for sorting $4 \mathrm{~mm}$ ): Overall dimensions: $1.5 \mathrm{~m} \times 4.5 \mathrm{~m}$, complete with: Rubber rollers, speed variator - device for roller rotation - platforms with ladders, lighting and electric installation.

- Cull Collecting Belt Placed below the roller floor.

- Cull Collection Conveyor 6 belts: overall dimensions: $1.5 \mathrm{~m}$ x $2.5 \mathrm{~m}$.

- Pre Aligner 6 lanes: Overall dimensions: $1.6 \mathrm{~m}$ x 2.5m: Belt conveyor with lining system for fruits. The machine is composed by couple of belts with different speeds, placed on reduced diameter pulleys to reduce the passages including motorization with different speeds

- Electronic Grading Machine Mod. Manager 6 Lanes, 4+1 Exit Sizing by Color and Diameter.

- Grading data of 1 st and 2 nd quality are sent to the main grader computer for statistic

Electronic grading machine with trolleys cups in soft rubber for the grading of delicate Fruits. Sized fruits are unloaded by means of motorized brushes or plastic flaps or directly (Sammo). Dry Bins Filler With Mobile Rotating Disk: Machine for the dry automated filling of steady bins. Complete with: automatic magneto-thermic cut-out witches automatic control equipment with stop/start control.

Figures 9-12 show the original pictures of fruits graded on the grading line. Royal delicious apples received from orchards of Himachal Pradesh (India) are graded using Sammo grader with Ellips software-Truesort. Chroma and Hue are used to control the segregation of Redness and greenness apples. L (Lightness), a (Redness or Greenness), b (Blue or Yellowness) are the basic parameters used for color grading. "A" positive indicates redness and negative indicates Greenness. "b" positive indicates yellowness and negative blueness. Most of the fruits turn to yellow and redness while ripening. Apple turns from green to red, however mango, banana and papaya, citrus fruits turn from green to yellow. The $\mathrm{L}$, a and $\mathrm{b}$ values change accordingly.

Total Color difference $(\Delta \mathrm{E})$ is calculated as

$$
(\Delta \mathbf{E})=\sqrt{ } \mathbf{L}^{2}+\mathbf{a}^{2}+\mathbf{b}^{2}
$$

This is used as a yardstick to specify the quality parameters on color.

Some of the apple color measurement in bulk is carried out and color acceptability is fixed based on customer acceptance. An organoleptic test is conducted to fix the color acceptability range for apples. Test was designed using nine point hedonic scale with 9 for extremely like and zero for extremely dislike. Fifteen experts from apple trading business were invited for the test. Test was conducted in a controlled lighting chamber as per the procedure described by Ramesh Babu and Das Gupta [22]. Samples are provided to the panelists from a standard 20kg CFB carton with five trays separating the layers. Orchard level manual grading is first assessed. Then fruits are graded on the grading line and assessed by the panel. Results are presented in table1. 
Table1: Comparison of color perception of royal delicious apples graded using manual and machine methods

\begin{tabular}{|c|c|c|c|}
\hline $\begin{array}{c}\text { Apple } \\
\text { Quality } \\
\text { manual }\end{array}$ & $\begin{array}{c}\text { Color perception } \\
\text { (Manual) }\end{array}$ & $\begin{array}{c}\text { Color perception(After grading on } \\
\text { machine) }\end{array}$ & $\begin{array}{c}\text { Red Color requirement } \\
\text { of apple traders }\end{array}$ \\
\hline Supreme (a) & $7.8 \pm 0.9^{\mathrm{a}, \mathrm{b}}$ & $8.9 \pm 0.1^{\text {ab }}$ & Above $90 \%$ \\
\hline AAA(b) & $7.9 \pm 0.8^{\mathrm{a}, \mathrm{b}, \mathrm{c}}$ & $8.8 \pm 0.1^{\mathrm{ab}}$ & 70 to $90 \%$ \\
\hline $\mathrm{AA}(\mathrm{c})$ & $8.2 \pm 0.3^{\mathrm{a}, \mathrm{b}, \mathrm{c}, \mathrm{d}}$ & $8.5 \pm 0.5^{\text {cd }}$ & 50 to $70 \%$ \\
\hline $\mathrm{A}(\mathrm{c})$ & $8.1 \pm 0.2^{\mathrm{a}, \mathrm{b}, \mathrm{c}, \mathrm{d}}$ & $8.1 \pm 0.4^{\text {cd }}$ & Below $50 \%$ \\
\hline
\end{tabular}

*Different superscripts (with a, b, c and d) are significantly different at 0.01 confidence level.

The panelists clearly identified the accuracy of color measurement of apples, which is indicated by the significant difference statistically. Above data can be useful for adding the correlations into the proposed automation system, so that the trader or consumer's perception is fed into the system for automatic segregation with accuracy.

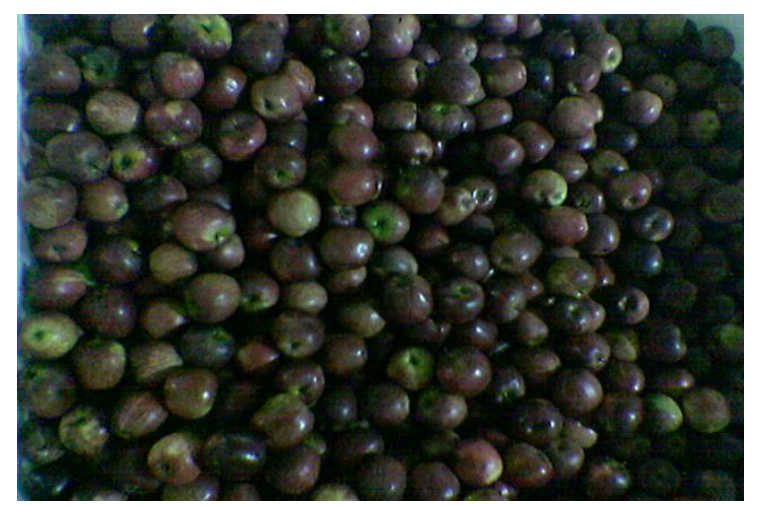

Figure 9: Apples with more than 90\% Red Color.

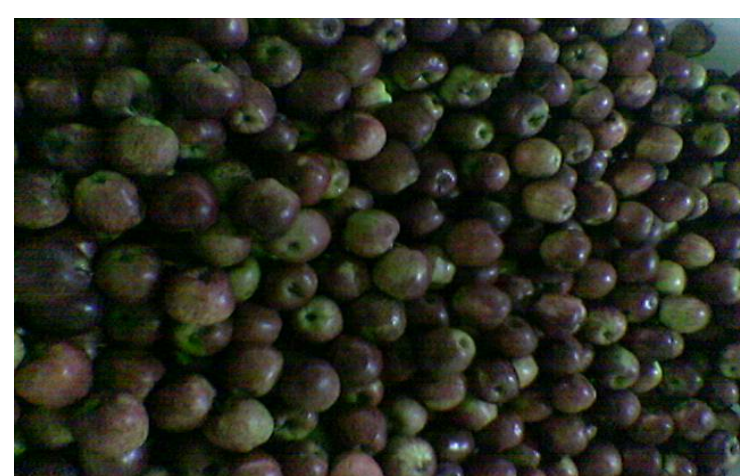

Figure 10: Apples with 70 to $90 \%$ Red Color

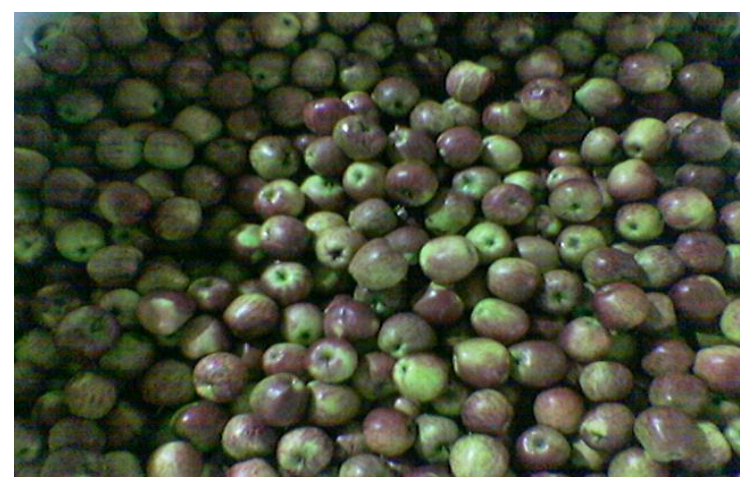

Figure 11: Apples with 50 to $70 \%$ Red Color 


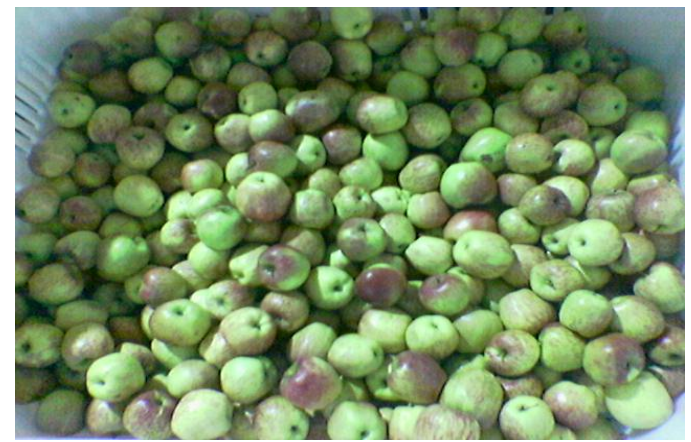

Figure 12: Apples with less than $50 \%$ Red Color

8. Software needs to be Installed with following Files, Modules and Registers for Material Handling. This is Required for Recording Arrival, Grading, Packing and Storage and Dispatch of Fruits

Table 1: Showing the software modules need to be prepared for integration, data communication and inventory management.

\begin{tabular}{|c|c|c|}
\hline $\begin{array}{l}\text { Sl. } \\
\text { No. }\end{array}$ & Activity & $\begin{array}{l}\text { Software record need } \\
\text { to be maintained }\end{array}$ \\
\hline 1 & $\begin{array}{l}\text { Arrival fruit Weighment: On reporting at the Store, Apple boxes are } \\
\text { weighed Unloading operations at sorting station }\end{array}$ & Inward Register module \\
\hline 2 & $\begin{array}{l}\text { Consignment details entered in the system/tab regarding sorted, graded } \\
\text { and packed fruits along with weighment }\end{array}$ & Box weighment module \\
\hline 3 & $\begin{array}{l}\text { Quality Test: The quality tests on samples of apples are performed on } \\
\text { calibrated instruments along with some chemical tests. The samples } \\
\text { are checked for quality from the incoming boxes lot wise. Check the } \\
\text { size, color, damages, and other poor quality of fruits. Typical } \\
\text { parameters checked are, firmness, Total soluble solids, maturity index, } \\
\text { color using chroma meter (Konica Minolta or similar) }\end{array}$ & $\begin{array}{l}\text { Quality module - } \\
\text { Tested by lab technician }\end{array}$ \\
\hline 4 & $\begin{array}{l}\text { Operation at grading line: Allotment of bin number identification and } \\
\text { filling the bins with loose apples. }\end{array}$ & $\begin{array}{l}\text { Inventory supervisor } \\
\text { module }\end{array}$ \\
\hline 5 & $\begin{array}{l}\text { Chamber loading with apple bins: System module of chamber filling } \\
\text { to record stacking pattern of bins inside cool chambers. }\end{array}$ & Chamber filling module \\
\hline 6 & $\begin{array}{l}\text { Inventories module for packed fruits. } \\
\text { Dispatch and Transportation module: This will record all deliveries of } \\
\text { fruits to the market }\end{array}$ & Dispatch Supervisor \\
\hline
\end{tabular}

\section{Water Flume System on Sorting-Grading Machines}

Water flume system will eliminate any mechanical damage while transferring apples from boxes, as water acts as conveying medium for movement of apples to the sorting-grading machine. Apples can be quickly transferred to the water tank, where water acts as cushion to the handling of apples. This will also reduce the cost of labor.

\section{Packing Lines}

Packing lines on the sorting-grading line will enable to pack the non-standard and non-categorized apples to be packed immediately (those apples which need not be stored or not-fit-for storage).

\section{CONCLUSIONS}

With the help of automatic and electronic systems for sorting, grading, record keeping and inventory management, the fruit storage operations can be efficiently handled. Monitoring and controlling software, PLC network, SCADA for HVAC 
software, PlantvisorPro (M/s Carel) or similar can be used to monitor temperature and humidity, gas conditions of fruits during storage. Quality parameters can be monitored using Color meter, Refractometer, Penetrometer and Maturity testing kits. In this study, apple color quality is measured by an expert panel organoleptic test and compared the data with automatic color grading system. Quality acceptance by the expert panel indicated a significant positive correlation with visual and colorimeter readings. A fruit storage plant must utilize mechanized systems for temperature management, gas control, material handling, sorting and grading to reduce manpower and improve efficiency. This aids in error proof technical and operations management. The results of this study will be helpful to devise a fully automatic warehouse management cold chain system. Future work can be taken up to design and integrate fruit quality testing, dynamic changes in the storage chamber, fruit volatiles measurement, material handling and storage.

\section{REFERENCES}

1. Madhu Sivaraman, "Government's role in India's ailing cold storage sector", Working Paper, (2016) December. DOI: 10.13140/RG.2.2.36370.45765

2. Vijay Paul and Rakesh Pandey, "Cold storage in India: Present Scenario and Future Directions", Processed Food Industry, (2016), May, pp. 25-29.

3. Minten, Bart and Reardon, Thomas and Singh, K.M. and Sutradhar, Rajib, "The benefit of cold storages: Evidence from Bihar, MPRA Paper No. 54345, (2010), posted on $13^{\text {th }}$ March 2014 available at https://mpra.ub.uni-muenchen.de/54345/

4. Narasimha Rao, K. V., Narasimham, G. S. V. L. and Krishna Murthy, M. V., "Analysis of Co-Current Hydraircooling of Food Products in Bulk”, Int. J. of Heat and Fluid Flow, (1992), vol.13, no.3, pp.300-310.

5. Narasimha Rao, K. V., Narasimham, G. S. V. L. and Krishna Murthy, M. V., "Parametric Study on the Bulk Hydraircooling of Spherical Food Products”, AIChE Journal, (1993a), vol. 39, no. 11, pp.1870-1884.

6. Narasimha Rao, K. V., Narasimham, G. S. V. L. and Krishna Murthy, M. V., "Analysis of heat and mass transfer during bulk hydraircooling of spherical food products”, Int. J. of Heat and Mass Transfer, (1993b), vol. 36, no. 3, pp. 809-822.

7. Ramesh Babu, D., Narasimha Rao, K. V., Satish Kumar, M. V. and Satish Kumar, B., "Handling of Apples During Sortinggrading Operation and Measuring the Mechanical Properties Firmness after Controlled Atmosphere Storage", International Journal of Mechanical and Production Engineering Research and Development (IJMPERD), (2018), vol. 8, no.6, pp. 617-634.

8. Ramesh Babu, D., Narasimha Rao, K. V. and Syam Kolati., "The Design of Refrigeration, Thermal Insulation and an Equipment for Healthy Ripening of Mango and Banana Without Using Harmful Chemicals", IJMPERD, (2019), Vol. 9, No 1, pp. 423-434.

9. D Ramesh Babu, Sireesha Koneru, K V Narasimha Rao, B Satish Kumar, Syam Kolati, N Suman Kumar, "Identifying Opportunities to start Industries on the Food Production Potential in Telangana and Andhra Pradesh, India", International Journal of Engineering and Advanced Technology, (2019), vol.8, no.5, pp.2189-2193.

10. D Ramesh Babu, Ram Deshmukh, $K$ V Narasimha Rao, M Rajya Laxmi, Kafila and T Sabita, "Awareness on Calcium Carbide Ripened Fruits and Recommendations for Toxic Free Artificial Ripening of Fruits", International Journal of Engineering and Advanced Technology, (2019), Vol.9, No. 2., pp. 2779-2782.

11. Ram Deshmukh, D Ramesh Babu and K V Narasimha Rao., "Pressure Testing Results (As A Decision Tool For Deciding Low Oxygen Or Ultra-Low Oxygen Or High Oxygen Storage) of Semi- Hermetically Sealed Controlled Atmosphere Storage Insulated Chambers", IJMPERD, (2020), Vol.10, No.1, pp. 531-540.

12. Naredla, S. K., Shekar, P. R., Babu, D. R., and Condoor, S., "Uniquely Addressing Customer Pain Points-the Case Study of 
Agritech”, App. International Journal of Mechanical Engineering and Technology, (2018), vol.9, no.11, pp. 2306-2314.

13. E. Ramesh, D. Ramesh Babu and P. Ramchandar Rao, "The Impact of Project Management in Achieving Project SuccessEmpirical Study”, International Journal of Mechanical Engineering and Technology, (2018), vol.9, no.13, pp. $237-247$.

14. P Sammaiah, D Ramesh Babu, L Radhakrishna, and P Rajendar, "Kinetics of Moisture Loss during Dehydration of Drum Stick Leaves (Moringa Oliefera) In a Bio-Mass Tray Dryer”, International Journal of Engineering and Advanced Technology, (2019), August, vol,8, no.6, pp.2937-2941.

15. Narasimha Rao KV, Shareef Shaik and Ramesh Babu. D, "Mathematical Modeling of Cooling Rates of Mango Fruits during Unsteady State Cooling in An Artificial Ripening Chamber”, Test Engineering and Management, (2020), March-April, vol 83, pp.6862-6871.

16. Narasimha Rao K V, Sasank Devarakonda and Ramesh Babu D, "Mathematical Modeling of Cooling Rates of Mango Fruits During Unsteady State Cooling in An Artificial Ripening Chamber”, Test Engineering and Management, (2020), March-April, vol 83, pp.6872-6879.

17. Sorting and grading lines, https://www.unisorting.com/en/products/potato-sorting-grading-packing-machines/

18. Fruit and vegetable grading technology, https://en.unitec-group.com/fruit-vegetables-technology/

19. Sorting, grading and packing lines, https://www.aweta.com/en/

20. Sorting, grading and packing lines, https://www.greefa.com/

21. Systems for controlled atmosphere storage, http://www.storagecontrol.com/

22. D Ramesh Babu and Das Gupta, DK (2005) Development of Pineapple Juice-Milk/Lassi Powders, Journal of Food Science and Technology-Mysore, 42(3)241-245.

\section{AUTHORS PROFILE}

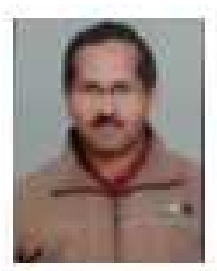

D. Ramesh Babu has got over 24 years of professional experience in manufacturing, research, maintenance, consultancy and project management of Refrigeration, Cold Storage and Controlled Atmosphere storage technologies.

He was graduated in Mechanical Engineering from JNTU College of Engineering, Hyderabad in the year 2000 and obtained MBA in production and operations management from MDU, Rohtak. He also obtained his MTech in Advanced Manufacturing from JNTU, Hyderabad. He has got expertise in refrigeration, fruit preservation and food processing. He is presently working as Assistant Professor in Mechanical Engineering at S R Engineering college, Warangal since year 2014. He has four years of experience in refrigeration equipment manufacturing at Voltas Limited, seven years of experience in fruit preservation at Defence food research laboratory, DRDO-Mysore and worked for eight years at cold chain project of CONCOR before joining teaching.

He is a recipient of DRDO cash award in the year 2003. He was nominated by CONCOR for eight days visit to ISRAEL as part of cold chain project for preservation of apples in the year 2011. He has published 4 research papers in 
SCI indexed journal, 15 papers in SCOPUS indexed journals and 6 in ICI indexed journals. He also presented numerous papers at various International and national conferences. His paper got best paper award by the TJPRC for the paper on "The Design of Refrigeration, Thermal Insulation and an Equipment for Healthy Ripening of Mango and Banana without Using Harmful Chemicals.” published in IJMPERD.

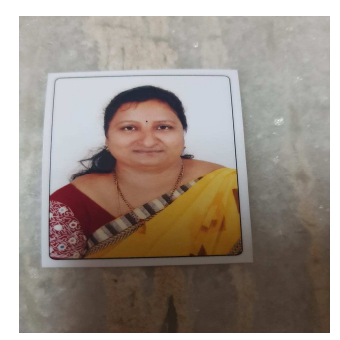

Dr.N. Gayatri obtained her Ph.D. degree in the area of Software Engineering in Computer Science Engineering, National Institute of Technology, Tiruchirappalli, India. She received her B.E. degree in Computer Science Engineering from Madras University and M.E. degree in Computer Science Engineering from SVCE affiliated to Anna University, Chennai. She has 7 years of teaching experience in reputed engineering colleges. Her research interest includes software Engineering, Data Mining and Data Science. She published 13 papers in various national, international journals and conferences.

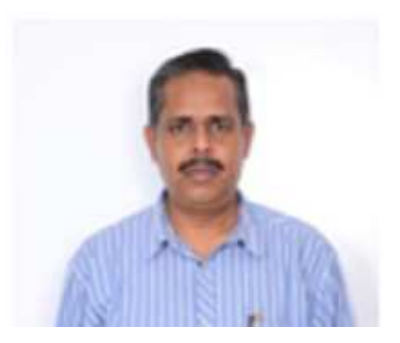

Dr P. Issac Prasad, has 22 years of experience and working as Professor in the Department of Mechanical Engineering, KLEF (Deemed to be University), Vaddeswaram. He obtained Doctoral degree from JNTUA in the field of Thermal Engineering. He acted as Thermal Engineering Research Group head in the Department of Mechanical Engineering, KLEF. He worked as Principal at two Engineering Institutions affiliated to JNTUK and JNTUA. Apart from conference, national and international publications, at present he is also acting as Associate Dean - IQAC, KLEF.

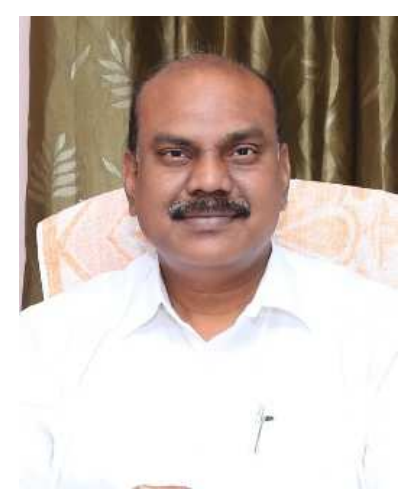

Dr S Jagan Mohan Rao has 29 years of work experience in teaching, research (Active power control of sub-merged arc furnaces for the production of Ferro-chrome and Ferro-silicon, and, Control of steam bus for 2 turbines) and industry (Power sector and Ferro alloys). Expertise in tailoring of Distributed Control Systems, Programmable Logic Controllers 
and SCADA systems.

He is Presently working as professor of ECE in Ramachandra College of Engineering, Eluru (Andhra Pradesh). Trainings had in DCS, Power medicine and fire fighting.

Projects: MODROB 2019 with an advance of Rs. 1286400.

IEDC projects at College: 2 .

Memberships: ISTE, IETE and IE.

Patents: Industrial Design (Parabolic Trough Collector) - Application no.: 329700-001 dt 30.05.20

ADD-ON COURSES TAUGHT:PLC Programming and Design of PCBs

PAPER PUBLICATIONS:About 20 plus papers

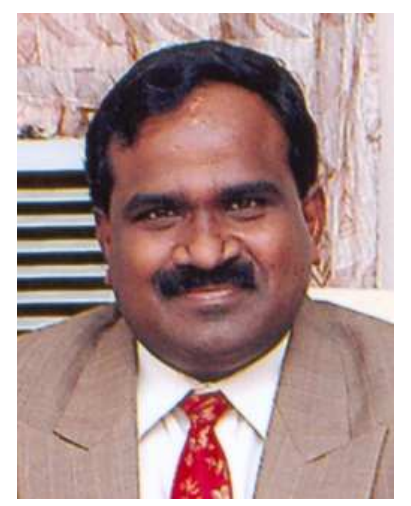

Dr K V Narasimha Rao is a senior Professor with 27+ years experience in Academic, Consultancy and Industry and has been working with KLEF (Deemed to be University) Vaddeswaram since 2 September 2016. Dr Narasimha Rao was graduated in Mechanical Engineering from Regional Engineering College, Warangal in 1986 and went on to obtain Master's and Doctoral degrees from the Indian Institute of Science, Bangalore during 1990 and 1995 respectively in the field of Thermal Engineering. He worked for seven years (1995-2002) as Research Associate and Fellow, Industrial Energy Group at Tata Energy Research Institute (teri), Southern Regional Centre, Bangalore before moving into Academics in 2002. Prior to joining KLEF, he worked at few Engineering Colleges as Principal/Director/Dean. Dr Rao has published 40 scientific papers (three in SCI Listed Journals, 30 Scopus indexed Journals and Chapter 10 in Recent Advances in Material Sciences, Lecture Notes on Multidisciplinary Industrial Engineering) and numerous technical reports for various National/International Agencies. HE has filed 14 patents (three published).

Membership of Professional Bodies:

Dr Rao is a member of ASHRAE, ISCA, ISHMT, ISHRAE, ISTE \& SESI and Fellow of Institution of Engineers (India).

Scholarships \& Awards:

- Recipient of 'National Merit Scholarship' during 1980-85 (6 Years).

- Recipient of 'Special Rank' in Mathematics Olympiad conducted by Andhra Pradesh Association of Mathematics Teachers (APAMT), Hyderabad, A. P. at Senior Level during 1980-81.

Areas of Specialization: 
- Energy Auditing, Energy Conservation \& Management, Heat Transfer, Refrigeration \& Air-conditioning and Renewable Energy Sources.

Research Guidance:

Supervised 14 M. Tech. Students and presently guiding Six PhD Scholars and four M. Tech. Students.

Important Projects handled:

- Dr Rao was the Team Leader for the Consultancy Assignment on Energy Efficiency Services-Phase-III (3 May30 November 1998), for the Ministry of Industry, His Majesty's Govt. of Nepal, Industrial Energy Management Component of the Power Sector Efficiency Project (PSEP) - IDA Credit No. 2347-NEP, World Bank. The activities included Demand Side Management (DSM), Furnace \& Kiln and Boiler Efficiency studies, Cogeneration Feasibility studies covering 65 major industries in Nepal. Trained 11 Nepalese Engineers as Certified Energy Auditors as part of the Consultancy Assignment.

- Dr Rao was involved in the field-testing of a number of Energy Saving Devices / Retrofits under the Energy Saving Demonstration Project, funded by GTZ, Germany.

- Dr Rao has developed and Demonstrated "Performance Contract for Industrial Energy Management" for Indian Scenario, sponsored by Canadian International Development Agency. 